\title{
Perinatal outcome of twin pregnancies according to maternal age
}

\author{
Yeon-joo Lee ${ }^{1,{ }^{*}}$, Mi-Na Kim 1, ${ }^{*}$, Yoo-Min Kim ${ }^{1}$, Ji-Hee Sung ${ }^{2}$, Suk-Joo Choi ${ }^{1}$, Soo-young Oh ${ }^{1}$, Cheong-Rae Roh ${ }^{1}$, \\ Jong-Hwa Kim ${ }^{1}$
}

Department of Obstetrics and Gynecology, ${ }^{1}$ Samsung Medical Center, ${ }^{2}$ Kangbuk Samsung Hospital, Sungkyunkwan University School of Medicine, Seoul, Korea

\section{Objective}

To investigate the perinatal outcomes of twin pregnancies according to maternal age.

Methods

This is a retrospective cohort study of twin pregnancies delivered $\geq 24$ weeks' gestation at a tertiary academic hospital from 1995 to 2016. Subjects were categorized into 5 groups according to maternal age: $<25,25-29,30-34,35-39$, and $\geq 40$ years. Maternal and neonatal outcomes of each maternal age group were analyzed using the Jonckheere-Terpstra test and the linear-by-linear association test.

Results

A total of 1,936 twin pregnant women were included, of which $47(2.4 \%), 470(24.3 \%), 948(49.0 \%), 417(21.5 \%)$, and $54(2.7 \%)$ women were aged $<25,25-29,30-34,35-39$, and $\geq 40$ years, respectively. Higher maternal age was significantly associated with a higher rate of dichorionic twins and a higher risk of gestational diabetes and placenta previa. However, rates of preterm labor, preterm premature rupture of membranes, cervical incompetence, preterm delivery, preeclampsia, placenta abruption, and cesarean section were not associated with maternal age. Birth weight increased and the rate of admission to the neonatal intensive care unit (NICU) decreased with older maternal age, but other neonatal outcomes did not change with age. Maternal age was significantly associated with a lower rate of NICU admission after controlling for potential confounding factors in multivariable analysis.

\section{Conclusion}

Advanced maternal age in twin pregnancies was associated with increased risk of gestational diabetes, placenta previa, and higher birth weight but a lower rate of NICU admission. However, other outcomes were not significantly associated with maternal age.

Keywords: Maternal age; Twin pregnancy, Perinatal care

\section{Introduction}

Advanced maternal age and twin pregnancy are major obstetric concerns with increasing worldwide incidence. The recent trend toward increased women's social participation and delayed childbearing has led to increased proportions of advanced-age pregnancies, multiple pregnancies, and the co-occurrence of both [1,2]. Live births among women aged 35 years or older increased steadily from $6.1 \%$ to $16.9 \%$ between 1985 and 2016 in the United States [3]. Maternal age has increased steadily in Korea over the past few decades, following the same trends as in many other developed
Received: 2018.06.26 Revised: 2018.09.27 Accepted: 2018.10.10. Corresponding author: Suk-Joo Choi

Department of Obstetrics and Gynecology, Samsung Medical Center, Sungkyunkwan University School of Medicine, 81 Irwonro, Gangnam-gu, Seoul 06351, Korea E-mail: drmaxmix.choi@samsung.com https://orcid.org/0000-0002-8946-4789

${ }^{\star}$ These authors contributed equally to this work.

Articles published in Obstet Gynecol Sci are open-access, distributed under the terms of the Creative Commons Attribution Non-Commercial License (http://creativecommons. org/licenses/by-nc/3.0/) which permits unrestricted non-commercial use, distribution, and reproduction in any medium, provided the original work is properly cited.

Copyright $\odot 2019$ Korean Society of Obstetrics and Gynecology 


\section{Obstetrics \& Gynecology Science}

Vol. 62, No. 2, 2019

countries [4]. The percentage of pregnancies in women over 35 years increased more than 3 -fold from $7.4 \%$ in 2001 to $26.4 \%$ in 2016 [5]. Along with changes in maternal age, advancements in and increased use of assisted reproductive technology (ART) have resulted in a higher frequency of multiple pregnancies $[6,7]$. The twin birth rate (twin births per 1,000 total births) increased by $78 \%$ from 18.9 in 1980 to 33.4 in 2016 in the United States [3]. The incidence of twin pregnancy in Korea increased from $2.4 \%$ in 2006 to $3.8 \%$ by 2016 [5]. The increase in twin pregnancy incidence among women of advanced maternal age is even more striking: from 2006-2016, the incidence of multiple pregnancies in Korea increased from $3.4 \%$ to $5.5 \%$ in women aged $35-39$ years and from $1.8 \%$ to $3.9 \%$ in women aged 40 years or older [5].

As the incidence of twin pregnancy in older women increases, concern grows over the risk of adverse perinatal outcomes. Prior studies have found that advanced maternal age is associated with increased risk of obstetric complications, such as intrauterine growth restriction, gestational diabetes, preterm birth, stillbirth, and cesarean section [8,9]. However, most of these studies were conducted with singleton pregnancies, and there are limited data regarding the association between maternal age and perinatal outcomes in twin pregnancies compared to singleton pregnancies. Furthermore, previous studies on this subject reached conflicting conclusions [10-12]. Currently, there are no data on the relationship between maternal age and twin-pregnancy outcomes in Korea. Thus, we investigated changes in the maternal age of women having twin pregnancies over a 22-year-study period at a single tertiary academic hospital in Korea and analyzed the associations between maternal age and perinatal outcomes in twin pregnancies.

\section{Materials and methods}

This is a retrospective cohort study of women with twin pregnancies who delivered at or beyond 24 weeks of gestation at a tertiary academic hospital between January 1995 and December 2016. We excluded pregnancies in which 1 or both fetuses died in utero before 24 weeks of gestation. Triplet or higher order multiple pregnancies were also excluded from the analysis. After exclusion, 1,936 cases were included in the study. Subjects were categorized into 5 groups based on age at the time of delivery: <25, 25-29, 30-34, 35-39, or $\geq 40$ years of age. This study was approved by the Institutional Review Board for Clinical Research at Samsung Medical Center.

Maternal demographic characteristics included maternal age at delivery, parity, history of prior preterm delivery, mode of conception (spontaneous vs. assisted conception), and chorionicity. Assisted conception included pregnancies achieved by in vitro fertilization. Chorionicity was established via sonographic findings, including gestational sac number, placental number, the presence of either a "twin-peak" or a " $T$ " sign, inter-twin membrane thickness, and fetal sex. Chorionicity status was confirmed by gross and/or pathologic examination of the placenta after delivery.

Pregnancy outcomes included fetal death in utero (FDIU), fetal congenital anomaly, gestational age at delivery, preterm delivery, preterm labor, preterm premature rupture of membranes (PPROM), placenta previa, placenta abruption, gestational diabetes, preeclampsia, twin-to-twin transfusion syndrome (TTTS), and delivery mode. Gestational age was calculated by the last menstrual period or by the crown-rump length measured during the first-trimester ultrasound. Preterm delivery was defined as a delivery that occurred before 37 weeks of gestation. The rates of preterm delivery at less than 37 weeks and less than 34 weeks of gestation were analyzed. PPROM was defined as rupture of the fetal membranes before 37 weeks of gestation. Cervical incompetence was defined as painless cervical dilatation with bulging of the fetal membranes; an incidental finding of short cervical length during routine ultrasonography was not considered cervical incompetence in this study.

Neonatal outcomes included birth weight, sex, Apgar scores, neonatal intensive care unit (NICU) admission, requirement of assisted ventilation, and neonatal mortality. Neonatal mortality was defined as neonatal death during the first 28 days of life. The neonatal morbidities analyzed were respiratory distress syndrome (RDS), bronchopulmonary dysplasia (BPD), grade 3-4 intraventricular hemorrhage $(\mathrm{IVH})$, periventricular leukomalacia (PVL), stage 2-3 necrotizing enterocolitis (NEC), suspected or proven early and late neonatal sepsis, grade 3-4 retinopathy of prematurity (ROP), patent ductus arteriosus (PDA), and transient tachypnea of the newborn (TTN). RDS was defined as the presence of respiratory distress, as indicated by an increased oxygen requirement $\left(\mathrm{FiO}_{2} \geq 0.4\right)$ and compatible chest radiographic 


\section{Obstetrics \& Gynecology Science}

Yeon-joo Lee, et al. Maternal age and twin pregnancy outcome

findings. BPD was defined as the need for supplementary oxygen for 28 days. IVH was diagnosed by brain ultrasonography and graded using the Papile classification system for intraventricular bleeding without (grade 2) or with ventricular dilatation (grade 3) or with parenchymal involvement (grade 4). PVL was defined as the presence of a cystic lesion and echogenicity in the periventricular white matter [13]. ROP was graded using the International Classification of ROP [14]. NEC was defined as an acquired neonatal acute intestinal necrosis of unknown etiology according to the modified Bell's staging criteria [15]. Neonatal sepsis was diagnosed based on the presence of a positive blood culture (proven sepsis) or positive laboratory evidence in clinically suspected neonates (suspected sepsis). Early or late sepsis was diagnosed when neonatal sepsis was confirmed within the first 7 days of life or after the first 7 days of life, respectively. PDA was defined as symptomatic ductus arteriosus necessitating pharmacological treatment, surgical ligation, or both.

The obtained data were analyzed using the Statistical Package for Social Sciences version 24 (SPSS Statistics; IBM Corp., Armonk, NY, USA). Individual women were the unit of analysis for pregnancy outcomes, and individual infants of twin pairs were the unit of analysis for neonatal outcomes. Trend analysis was used to determine the trend of each outcome variable according to the 5 different maternal age groups. The Jonckheere-Terpstra test and linear-by-linear regression were used for continuous and categorical variables, respectively. Multiple logistic regression analysis was performed to evaluate the effects of potential confounding variables, such as neonatal sex, chorionicity, gestational diabetes, gestational age at delivery, and delivery mode, on the rate of NICU admission. The $P$-values $<0.05$ were considered statistically significant.

\section{Results}

During the 22-year study period, 1,985 (3.6\%) twin deliveries were identified out of 54,914 deliveries performed in our hospital. Forty-nine cases were excluded according to the exclusion criteria, and 1,936 twin pregnancy cases were ultimately included in our analyses. Among them, 47 (2.4\%), 470 (24.3\%), 948 (49.0\%), 417 (21.5\%), and 54 (2.7\%) women were aged $<25,25-29,30-34,35-39$, and $\geq 40$ years, respectively.

Fig. 1 shows the annual number of twin births and the proportion of twin births per total births from 1995-2016. The number of twin births increased until 2003 and then decreased along with a recent decrease in Korea's national birth rate. However, the proportion of twin births per total births increased by 4 times from $1.4 \%$ in 1995 to $5.6 \%$ in 2016. A similar trend was seen in the rate of twin births in women with advanced maternal age (Fig. 2). While the number and proportion of twin births in women aged $<35$ years decreased from 2003-2016, the proportion of twin births in women $\geq 35$ years has gradually increased, reaching $44.2 \%$

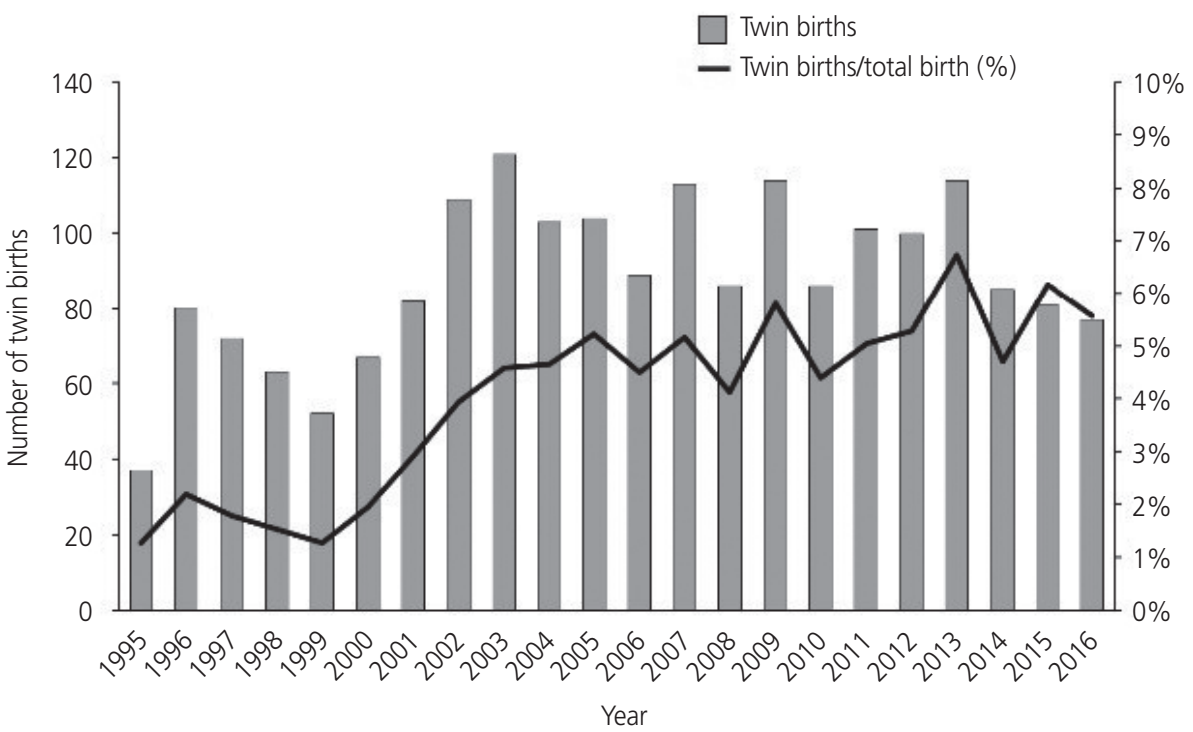

Fig. 1. Numbers and rates of twin birth. 


\section{Obstetrics \& Gynecology Science}

Vol. 62, No. 2, 2019

in 2016 compared with $18.9 \%$ in 1995.

The demographic and obstetric characteristics of each maternal age group are shown in Table 1. The rate of twin pregnancies conceived by ART increased significantly; therefore, the proportion of dichorionic twins also increased significantly with higher maternal age.

Table 2 shows pregnancy outcomes by maternal age group. Gestational diabetes and placenta previa incidences increased with increasing maternal age, whereas the incidences of other pregnancy outcomes, such as preterm delivery, preterm labor, PPROM, preeclampsia, placenta abruption, TTTS, FDIU, major congenital anomaly, and delivery mode, were not sig- nificantly different among the maternal age groups.

The outcomes of live-born twin infants in each maternal age group are described in Table 3. Birth weight significantly increased with advancing maternal age. The incidence of small-for-gestational age decreased, while the incidence of large-for-gestational age increased with advancing maternal age, though these trends were not statistically significant. There were no significant differences in the proportion of low Apgar scores, use of ventilator treatment, or neonatal mortality among maternal age groups. However, the rate of NICU admission significantly decreased with advancing maternal age. There were no statistically significant differences

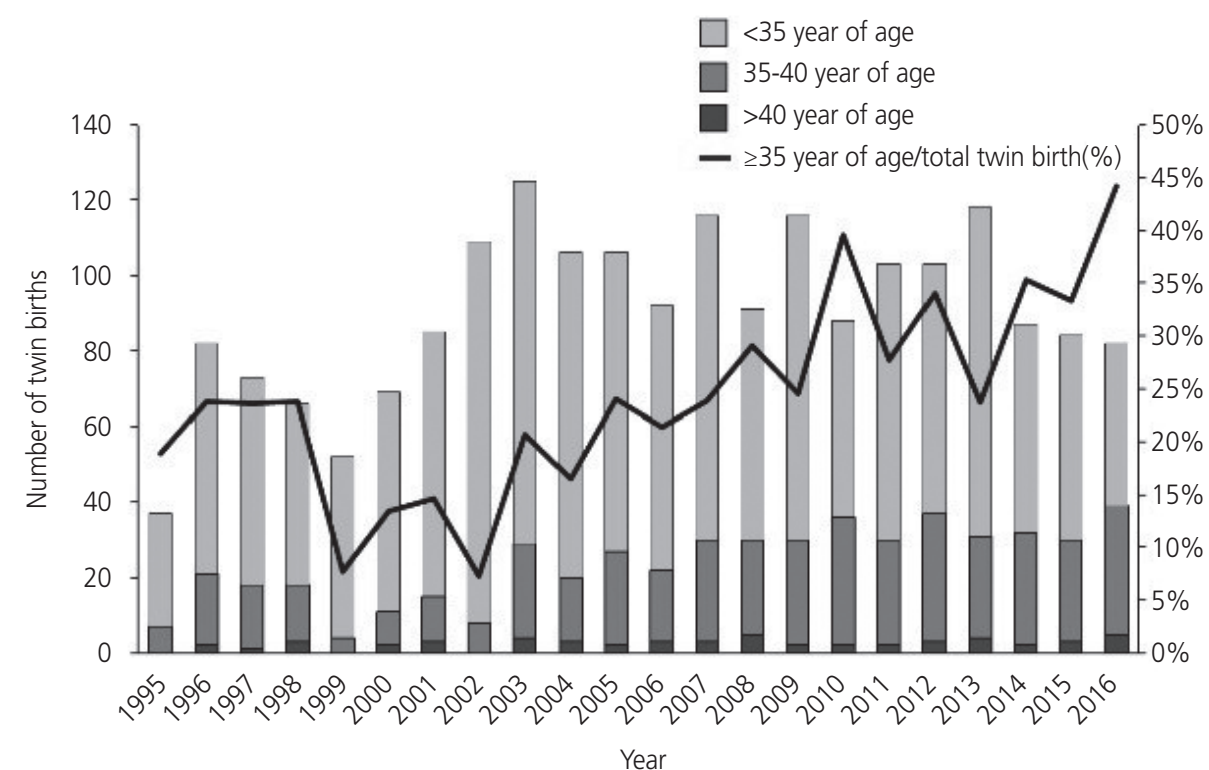

Fig. 2. Numbers and rates of twin births according to the maternal age.

Table 1. Maternal characteristics

\begin{tabular}{|c|c|c|c|c|c|c|}
\hline \multirow{2}{*}{ Characteristics } & \multicolumn{5}{|c|}{ Maternal age at delivery } & \multirow{2}{*}{$P$-value ${ }^{\text {a) }}$} \\
\hline & $<25$ yr $(n=47)$ & $25-29$ yr $(n=470)$ & $30-34$ yr $(n=948)$ & $35-39$ yr $(n=417)$ & $\geq 40$ yr $(n=54)$ & \\
\hline Maternal age (yr) & $22.9 \pm 1.7$ & $27.7 \pm 1.2$ & $32.0 \pm 1.4$ & $36.4 \pm 1.3$ & $41.7 \pm 2.9$ & $<0.001$ \\
\hline Muliparity & $5(10.6)$ & $73(15.5)$ & $239(25.2)$ & $132(31.7)$ & $20(37.0)$ & $<0.001$ \\
\hline History of preterm delivery & $1(2.1)$ & $8(1.7)$ & $39(4.1)$ & $21(5.0)$ & $3(5.6)$ & 0.007 \\
\hline Assisted conception & $3(6.4)$ & $121(25.7)$ & $499(52.6)$ & $284(68.1)$ & $33(61.1)$ & $<0.001$ \\
\hline Chorionicity $^{\mathrm{b})}$ & & & & & & $<0.001$ \\
\hline Monoamnionic & $0(0.0)$ & $7(1.5)$ & $4(0.4)$ & $1(0.2)$ & $0(0.0)$ & \\
\hline Monochorionic diamnionic & $28(60.9)$ & $145(31.9)$ & $239(25.3)$ & $67(16.1)$ & $10(18.9)$ & \\
\hline Dichorionic diamnionic & $18(39.1)$ & 302 (66.5) & $702(74.3)$ & 347 (83.6) & $43(81.1)$ & \\
\hline
\end{tabular}

Data are presented by mean \pm standard deviation or number (\%).

a) Jonckheere-Terpstra test for continuous variables and linear-by-linear association for categorical variables; ${ }^{\text {b) }}$ Cases with unknown chorionicity are excluded. 


\section{Obstetrics \& Gynecology Science}

Yeon-joo Lee, et al. Maternal age and twin pregnancy outcome

in the rates of RDS, BPD, IVH ( $\geq$ grade 3 ), PVL, NEC ( $\geq$ stage 2 ), early and late sepsis, ROP ( $\geq$ grade 3 ), PDA, and TTN among maternal age groups (Table 4). In multivariable analysis, advanced maternal age, advanced gestational age at delivery, and cesarean section were significantly associated with a decreased risk of NICU admission (Table 5). We compared the perinatal outcomes according to maternal age groups between monochorionic and dichorionic twin pregnancies,

Table 2. Pregnancy outcomes

\begin{tabular}{|c|c|c|c|c|c|c|}
\hline \multirow{2}{*}{ Characteristics } & \multicolumn{5}{|c|}{ Maternal age at delivery } & \multirow{2}{*}{$P$-value ${ }^{\text {a) }}$} \\
\hline & $<25$ yr $(\mathrm{n}=47)$ & $25-29$ yr $(n=470)$ & $30-34$ yr $(n=948)$ & $35-39$ yr $(n=417)$ & $\geq 40$ yr $(n=54)$ & \\
\hline Gestational diabetes & $1(3.1)$ & $10(2.9)$ & $60(7.5)$ & $44(12.5)$ & $9(19.6)$ & $<0.001$ \\
\hline Preeclampsia & $6(12.8)$ & $38(8.1)$ & $96(10.1)$ & $44(10.6)$ & $5(9.3)$ & 0.464 \\
\hline Placenta previa & $0(0.0)$ & $3(0.6)$ & $23(2.4)$ & $13(3.1)$ & $3(5.6)$ & 0.001 \\
\hline Placenta abruption & $0(0.0)$ & $11(2.3)$ & $28(3.0)$ & $11(2.6)$ & $4(7.4)$ & 0.125 \\
\hline Fetal congenital anomaly ${ }^{b)}$ & $4(8.5)$ & $23(4.9)$ & $51(5.4)$ & $25(6.0)$ & $4(7.4)$ & 0.613 \\
\hline$F D I U^{b)}$ & $0(0.0)$ & $12(2.6)$ & $20(2.1)$ & $5(1.2)$ & $1(1.9)$ & 0.396 \\
\hline TTTS & $0(0.0)$ & $15(3.2)$ & $13(1.4)$ & $6(1.4)$ & $2(3.7)$ & 0.378 \\
\hline Preterm labor & $22(46.8)$ & $170(36.2)$ & $325(34.3)$ & $134(32.1)$ & $20(37.0)$ & 0.121 \\
\hline PPROM & $14(29.8)$ & $86(18.3)$ & $178(18.8)$ & $73(17.5)$ & $10(18.5)$ & 0.327 \\
\hline Cervical incompetence & $3(6.4)$ & $10(2.1)$ & $41(4.3)$ & $24(5.8)$ & $1(1.9)$ & 0.103 \\
\hline GA at delivery (wk) & $34.0 \pm 3.7$ & $34.7 \pm 3.5$ & $34.9 \pm 3.4$ & $34.7 \pm 3.6$ & $35.1 \pm 2.6$ & 0.209 \\
\hline Preterm delivery <37 wk & $38(80.9)$ & $335(71.3)$ & $616(65.0)$ & $273(65.5)$ & $42(77.8)$ & 0.100 \\
\hline Preterm delivery <34 wk & $18(38.3)$ & $137(29.1)$ & $254(26.8)$ & $111(26.6)$ & $11(20.4)$ & 0.068 \\
\hline Cesarean section & $40(85.1)$ & $422(89.8)$ & $846(89.2)$ & $378(90.6)$ & $49(90.7)$ & 0.414 \\
\hline
\end{tabular}

Data are presented by mean \pm standard deviation or number (\%).

FDIU, fetal death in utero; TTTS, twin-to-twin transfusion syndrome; PPROM, preterm premature rupture of membranes; GA, gestational age.

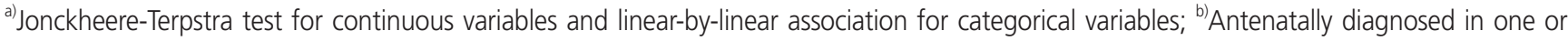
more twin pairs.

Table 3. Neonatal outcomes

\begin{tabular}{|c|c|c|c|c|c|c|}
\hline \multirow[b]{2}{*}{ Characteristics } & \multicolumn{5}{|c|}{ Maternal age at delivery } & \multirow[b]{2}{*}{$P$-value ${ }^{\text {a) }}$} \\
\hline & $<25$ yr $(n=94)$ & $\begin{array}{l}25-29 \mathrm{yr} \\
(\mathrm{n}=928)\end{array}$ & $\begin{array}{c}30-34 \text { yr } \\
(n=1,876)\end{array}$ & $\begin{array}{l}35-39 y r \\
(n=829)\end{array}$ & $\geq 40$ yr $(n=106)$ & \\
\hline Birth weight (kg) & $1.93 \pm 0.59$ & $2.10 \pm 0.62$ & $2.17 \pm 0.60$ & $2.15 \pm 0.66$ & $2.31 \pm 0.52$ & $<0.001$ \\
\hline Percentile of weight for GA & & & & & & 0.092 \\
\hline Small-for-GA & $14(14.9)$ & $114(12.3)$ & $191(10.2)$ & $105(12.7)$ & $8(7.5)$ & \\
\hline Large-for-GA & $1(1.1)$ & $90(9.7)$ & $151(8.0)$ & $85(10.3)$ & $13(12.3)$ & \\
\hline Sex (male) & $52(55.3)$ & $420(45.3)$ & $901(48.0)$ & 405 (48.9) & $51(48.1)$ & 0.457 \\
\hline 1-min Apgar score <4 & $7(7.4)$ & $57(6.1)$ & $76(4.1)$ & $38(4.6)$ & $7(6.6)$ & 0.156 \\
\hline 5-min Apgar score <7 & $4(4.3)$ & $67(7.2)$ & $81(4.3)$ & $43(5.2)$ & $4(3.8)$ & 0.072 \\
\hline NICU admission & $59(62.8)$ & $469(50.5)$ & $815(43.4)$ & $340(41.0)$ & $38(35.8)$ & $<0.001$ \\
\hline Mechanical ventilator & $27(29.0)$ & $208(22.4)$ & $371(19.8)$ & $195(23.5)$ & $19(17.9)$ & 0.518 \\
\hline Neonatal mortality & $3(3.2)$ & $14(1.5)$ & $22(1.2)$ & $12(1.4)$ & $1(0.9)$ & 0.394 \\
\hline
\end{tabular}

Data are presented by mean \pm standard deviation or number (\%)

GA, gestational age; NICU, neonatal intensive care unit.

a) Jonckheere-Terpstra test for continuous variables and linear-by-linear association for categorical variables. 


\title{
Obstetrics \& Gynecology Science
}

\author{
Vol. 62, No. 2, 2019
}

Table 4. Neonatal morbidities

\begin{tabular}{|c|c|c|c|c|c|c|}
\hline \multirow[b]{2}{*}{ Characteristics } & \multicolumn{5}{|c|}{ Maternal age at delivery } & \multirow[b]{2}{*}{$P$-value ${ }^{\text {a) }}$} \\
\hline & $<25$ yr $(n=94)$ & $\begin{array}{l}25-29 y r \\
(n=928)\end{array}$ & $\begin{array}{c}30-34 \text { yr } \\
(n=1,876)\end{array}$ & $\begin{array}{c}35-39 \mathrm{yr} \\
(\mathrm{n}=829)\end{array}$ & $\begin{array}{c}\geq 40 \mathrm{yr} \\
(n=106)\end{array}$ & \\
\hline RDS & $14(14.9)$ & $155(16.7)$ & $282(15.0)$ & $152(18.3)$ & $12(11.3)$ & 0.786 \\
\hline BPD & $9(9.7)$ & $56(6.0)$ & $104(5.5)$ & $60(7.2)$ & $5(4.7)$ & 0.970 \\
\hline IVH ( $\geq$ grade 3 ) & $2(2.2)$ & $15(1.6)$ & $22(1.2)$ & $13(1.6)$ & $0(0)$ & 0.392 \\
\hline$P V L$ & $1(1.1)$ & $10(1.1)$ & $22(1.2)$ & $13(1.6)$ & $2(1.9)$ & 0.292 \\
\hline NEC ( $\geq$ stage 2 ) & $1(1.1)$ & $15(1.6)$ & $39(2.1)$ & $16(1.9)$ & $2(1.9)$ & 0.528 \\
\hline Early sepsis & $6(6.5)$ & $64(6.9)$ & $101(5.4)$ & $53(6.4)$ & $6(5.7)$ & 0.575 \\
\hline Late sepsis & $4(4.3)$ & $46(5.0)$ & $78(4.2)$ & $48(5.8)$ & $2(1.9)$ & 0.899 \\
\hline ROP ( $\geq$ grade 3 ) & $0(0)$ & $26(2.8)$ & $37(2.0)$ & $25(3.0)$ & $2(1.9)$ & 0.536 \\
\hline PDA & $14(14.9)$ & $143(15.4)$ & $219(11.7)$ & $119(14.4)$ & $9(8.5)$ & 0.158 \\
\hline Transient tachypnea of newborn & $5(5.3)$ & $23(2.5)$ & $51(2.7)$ & $23(2.8)$ & $3(2.8)$ & 0.814 \\
\hline
\end{tabular}

Data are presented by mean \pm standard deviation or number (\%).

RDS, respiratory distress syndrome; BPD, bronchopulmonary dysplasia; IVH, intraventricular hemorrhage; PVL, periventricular leukomalacia; NEC, necrotizing enterocolitis; ROP, retinopathy of prematurity; PDA, patent ductus arteriosus.

a) Jonckheere-Terpstra test for continuous variables and linear-by-linear association for categorical variables.

Table 5. Multiple logistic regression analyses of neonatal intensive care unit admission rate controlling for potential confounding variables

\begin{tabular}{lcc}
\hline Variables & Adjusted OR (95\% Cl) & P-value \\
\hline Maternal age at delivery & $0.943(0.915-0.971)$ & $<0.001$ \\
Dichorionic twin & $0.823(0.641-1.057)$ & 0.128 \\
Gestational diabetes & $0.695(0.453-1.066)$ & 0.096 \\
GA at delivery & $0.845(0.835-0.856)$ & $<0.001$ \\
Cesarean section & $1.539(1.036-2.287)$ & 0.033 \\
Male baby & $1.095(0.878-1.365)$ & 0.423 \\
\hline
\end{tabular}

$\mathrm{OR}$, odds ratio; $\mathrm{Cl}$, confidence interval; $\mathrm{GA}$, gestational age.

respectively. Overall, the results were similar to those of the total study population. However, no difference in the birth weight according to maternal age groups was noted in the monochorionic twin pregnancies, and the rates of preterm delivery $<34$ weeks of gestation, 5 -minute Apgar score $<7$, and PDA significantly decreased with advancing maternal age in the dichorionic twin pregnancies (data not shown).

\section{Discussion}

This retrospective cohort study aimed to evaluate the influence of maternal age on pregnancy and perinatal outcomes in twin pregnancies. The risk of adverse pregnancy outcomes for twin pregnancy generally did not increase with advancing maternal age, except for gestational diabetes and placenta previa. Notably, in terms of neonatal outcomes such as birth weight and NICU admission, twins of older mothers had more favorable outcomes compared to twins of younger mothers.

It is well known that advanced maternal age is associated with an increased risk of adverse perinatal outcomes for singleton pregnancies [16]. However, for twin pregnancies, the impact of maternal age on perinatal outcomes is less obvious. Although some studies have shown that advanced maternal age was associated with higher risk of perinatal outcomes such as cesarean section, hypertensive disorder, and longer NICU admission [12], many other studies found no significant effect of maternal age on twin pregnancy outcomes $[11,17,18]$.

There are numerous possible reasons why the influence of maternal age on pregnancy and perinatal outcomes varies between twin and singleton pregnancies. First, twin pregnancy itself is known to be associated with a higher risk of many obstetric complications, including preeclampsia, gestational diabetes, and preterm delivery. Since the physiologic changes and complication mechanisms may differ between singleton and twin pregnancies, the effect of maternal age on singleton pregnancies cannot simply be extrapolated to twin 


\section{Obstetrics \& Gynecology Science}

Yeon-joo Lee, et al. Maternal age and twin pregnancy outcome

pregnancies [19]. Second, chorionicity difference may play a role. Pregnancy conceived via ART is more common among older women and more likely to result in dichorionic twinning. Given that monochorionic twins are at greater risk of adverse outcomes than are dichorionic twins, including TTTS, fetal death, fetal anomaly, preterm birth, and neuromorbidity, chorionicity differences by maternal age may affect the age-related risk for twin pregnancy $[20,21]$. In our data, the rates of placenta previa, TTTS, preterm delivery $<37$ weeks of gestation, small-for-gestational age, 1-minute Apgar score $<4,5$-minute Apgar score $<7$, and NICU admission were significantly higher in monochorionic twin pregnancies than in dichorionic twin pregnancies, while the rates of gestational diabetes and cervical incompetence were significantly higher in dichorionic twin pregnancies than in monochorionic twin pregnancies (data not shown). Third, a twin pregnancy in an older woman is generally considered a high-risk pregnancy on its own, which typically results in those women having more frequent antenatal visits and greater adherence to a healthy lifestyle. These behaviors may have influenced the favorable outcomes observed in the advanced maternal age pregnancies [22]. However, due to the limitations of a retrospective study, there was insufficient information on each patient's lifestyle behavior and antenatal visit patterns in this study.

Nevertheless, the rates of gestational diabetes and placenta previa increased with advancing maternal age in our study. Consistent with our results, Ananth et al. [23] reported a higher placenta previa rate in twin pregnancies compared with singleton pregnancies, as well as an increased placenta previa rate with advancing maternal age. Recent studies have identified several risk factors of placenta previa, such as parity, previous cesarean section, advanced maternal age, and multiple pregnancies [23-25]. A possible explanation for the increased placenta previa risk is that the placenta size for a twin pregnancy is larger than that of a singleton pregnancy [26]. Advanced maternal age pregnancies often have decreased uterine blood flow, and the need for a larger placental surface for adequate blood flow during pregnancy may be the reason for increased placenta previa $[27,28]$. Alternatively, ART has been identified as a placenta previa risk factor [29]. It has also been suggested that embryo transfer may cause uterine contractions during the ART procedure, resulting in a higher incidence of uterine lower-segment implantation [30]. For decades, it has been recognized that women of advanced maternal age have a higher rate of gestational diabetes [24,31,32]; however, this could also be explained by progressive vascular endothelial damage with increasing age [27]. Consistent with our study results, Zhu et al. [33] reported that advanced maternal age in twin pregnancy was associated with increased gestational diabetes.

Interestingly, our results indicate that twins from older women had more favorable outcomes in terms of higher birth weight and lower NICU admission rates. Several studies have reported that birth weight increases with increasing maternal age, both in singleton and multiple pregnancies $[22,34]$. The reason for increased birth weight with advancing maternal age is not fully understood. The effect of maternal age on birth weight may have been influenced by higher parity, increased maternal weight, better socioeconomic circumstances, better health behaviors, more frequent pregnancies by ART, and more concerned prenatal surveillances [22,35-37]. Although we cannot fully explain the lower risk of NICU admission with advanced maternal age, higher birth weights may play a role. In general, monochorionic twins experience increased risk of fetal death, fetal anomaly, preterm birth, and intrauterine growth restriction compared with dichorionic twins $[20,21,38]$. As maternal age increases, the increases in ART pregnancy and dichorionic twins may explain the lower NICU admission rate. However, in the multiple logistic regression analyses, maternal age was significantly associated with NICU admission, independent of chorionicity. Other studies have suggested that some perinatal outcomes, such as a lower risk of neonatal and perinatal death, lower rate of preterm birth, and higher birth weight, were more favorable in twin pregnancies of advanced maternal age $[11,34]$.

Advanced maternal age is generally defined as older than 35 years, but this definition is mostly based on an estimate of the risk of fetal loss after genetic amniocentesis and the risk of aneuploidy [39]. However, in this context, the definition of advanced maternal age for twin pregnancies may not be the same as for singleton pregnancies, because the age cut-off for genetic amniocentesis in dichorionic twin pregnancies is 31 years [40]. Therefore, we did not categorize the patients into 2 groups using the 35-year mark. Instead, we categorized the patients into more detailed groups to better analyze the age-related risk of adverse pregnancy outcomes and found that the impact of maternal age gradually changed with increasing age rather than yielding an increased risk at a 


\section{Obstetrics \& Gynecology Science}

Vol. 62, No. 2, 2019

specific age. Our analyses were possible because of our large sample size, which is a major strength of the study. Nevertheless, our sample size may still be insufficient to analyze all perinatal outcomes, especially among women aged $<25$ years and women aged $\geq 40$ years.

Our study has other limitations. First, its retrospective nature might have limited our ability to control for potential confounding factors and information biases, such as preconceptional comorbidities, socioeconomic status, educational status, alcohol consumption, and smoking. Second, potential selection bias and generalizability problems may be present because our institution is a tertiary care center. Whereas older women's pregnancies are generally considered high-risk, younger women with uncomplicated pregnancies are less likely to visit a tertiary care center. This may result in an overrepresentation of higher risk pregnancies in the younger age groups compared with the older age groups. Third, because our study only included cases that delivered after 24 weeks, the risk of abortion or FDIU with delivery $<24$ weeks according to maternal age was not studied. For similar reasons, we also did not analyze the age-related risk of congenital anomaly in this study, because pregnancy termination before 24 weeks was not included. Lastly, because our data were accumulated over 22 years, the management of twin pregnancies and twin infants may not have been consistent.

In conclusion, our findings suggest that, for twin pregnancies, maternal age is not associated with increased risk of adverse pregnancy and perinatal outcomes, except for gestational diabetes and placenta previa. Rather, twins are associated with more favorable perinatal outcomes with increasing maternal age. Although the cause of this paradoxical phenomenon in twin pregnancies remains unknown, the results of our study may help clinicians provide better pregnancy and perinatal counseling to older women carrying twin pregnancies.

\section{Acknowledgements}

This study was supported in part by the Korea Health Technology R\&D Project through the Korea Health Industry Development Institute (KHIDI), funded by the Ministry of Health \& Welfare, Republic of Korea (grant number: HI14C0306).

\section{Conflict of interest}

No potential conflict of interest relevant to this article was reported.

\section{Ethical approval}

This study was approved by the Institutional Review Board (IRB) for Clinical Research at Samsung Medical Center (IRB No. 2018-05-191-001) and performed in accordance with the principles of the Declaration of Helsinki. Written informed consents were obtained.

\section{References}

1. Carolan M. The graying of the obstetric population: implications for the older mother. J Obstet Gynecol Neonatal Nurs 2003;32:19-27.

2. Yogev Y, Melamed N, Bardin R, Tenenbaum-Gavish K, Ben-Shitrit G, Ben-Haroush A. Pregnancy outcome at extremely advanced maternal age. Am J Obstet Gynecol 2010;203:558.e1-558.e7.

3. Joyce A, Martin JA, Hamilton BE, Osterman MJK, Driscoll AK, Drake P. Births: final data for 2016. Natl Vital Stat Rep 2018;67:1-55.

4. Sohn K. Parents are rapidly getting older in South Korea. Hum Fertil (Camb) 2017;20:212-6.

5. Korean Statistical Information Service. Birth data for 2016, Korea. Daejeon: Korean Statistical Information Service; 2017.

6. Black M, Bhattacharya S. Epidemiology of multiple pregnancy and the effect of assisted conception. Semin Fetal Neonatal Med 2010;15:306-12.

7. Templeton A. The multiple gestation epidemic: the role of the assisted reproductive technologies. Am J Obstet Gynecol 2004;190:894-8.

8. Hoffman MC, Jeffers S, Carter J, Duthely L, Cotter A, González-Quintero VH. Pregnancy at or beyond age 40 years is associated with an increased risk of fetal death and other adverse outcomes. Am J Obstet Gynecol 2007;196:e11-3.

9. Huang L, Sauve R, Birkett N, Fergusson D, van Walraven C. Maternal age and risk of stillbirth: a systematic re- 


\section{Obstetrics \& Gynecology Science}

Yeon-joo Lee, et al. Maternal age and twin pregnancy outcome

view. CMAJ 2008;178:165-72.

10. McLennan AS, Gyamfi-Bannerman C, Ananth CV, Wright JD, Siddiq Z, D'Alton ME, et al. The role of maternal age in twin pregnancy outcomes. Am J Obstet Gynecol 2017;217:80.e1-80.e8.

11. Lisonkova S, Joseph KS, Bell R, Glinianaia SV. Effect of advanced maternal age on perinatal outcomes in twins: the impact of chorionicity. Ann Epidemiol 2013;23:42834.

12. Gluck O, Mizrachi Y, Bar J, Barda G. The impact of advanced maternal age on the outcome of twin pregnancies. Arch Gynecol Obstet 2018;297:891-5.

13. de Vries LS, Eken P, Dubowitz LM. The spectrum of leukomalacia using cranial ultrasound. Behav Brain Res 1992;49:1-6.

14. Retinopathy of prematurity: guidelines for screening and treatment. The report of a joint working party of The Royal College of Ophthalmologists and the British Association of Perinatal Medicine. Early Hum Dev 1996;46:239-58.

15. Lee JS, Polin RA. Treatment and prevention of necrotizing enterocolitis. Semin Neonatol 2003;8:449-59.

16. Kenny LC, Lavender T, McNamee R, O'Neill SM, Mills T, Khashan AS. Advanced maternal age and adverse pregnancy outcome: evidence from a large contemporary cohort. PLoS One 2013;8:e56583.

17. Prapas N, Kalogiannidis I, Prapas I, Xiromeritis P, Karagiannidis A, Makedos $G$. Twin gestation in older women: antepartum, intrapartum complications, and perinatal outcomes. Arch Gynecol Obstet 2006;273:293-7.

18. Fox NS, Rebarber A, Dunham SM, Saltzman DH. Outcomes of multiple gestations with advanced maternal age. J Matern Fetal Neonatal Med 2009;22:593-6.

19. Helle $\mathrm{S}$. Why twin pregnancies are more successful at advanced than young maternal age? A potential role of 'terminal reproductive investment'. Hum Reprod 2008;23:2387-9.

20. Yu HY, Lau T, Sahota DS, Ting Y, Leung T. Perinatal outcome of monochorionic twin pregnancies. Zhonghua Fu Chan Ke Za Zhi 2013;48:405-10.

21. Al Riyami N, Al-Rusheidi A, Al-Khabori M. Perinatal outcome of monochorionic in comparison to dichorionic twin pregnancies. Oman Med J 2013;28:173-7.

22. Zhang J, Meikle S, Grainger DA, Trumble A. Multifetal pregnancy in older women and perinatal outcomes. Fer- til Steril 2002;78:562-8.

23. Ananth CV, Demissie K, Smulian JC, Vintzileos AM. Placenta previa in singleton and twin births in the United States, 1989 through 1998: a comparison of risk factor profiles and associated conditions. Am J Obstet Gynecol 2003;188:275-81.

24. Cleary-Goldman J, Malone FD, Vidaver J, Ball RH, Nyberg DA, Comstock $\mathrm{CH}$, et al. Impact of maternal age on obstetric outcome. Obstet Gynecol 2005;105:98390.

25. Johnston R, Fong A, Lovell S, Sobolewski PS, Rad S, Turner A. Demographic and obstetric outcomes of pregnancies conceived by assisted reproductive technology (ART) compared to non-ART pregnancies. JBRA Assist Reprod 2015;19:16-20.

26. Strong TH Jr, Brar HS. Placenta previa in twin gestations. J Reprod Med 1989;34:415-6.

27. Crawford BS, Davis J, Harrigill K. Uterine artery atherosclerotic disease: histologic features and clinical correlation. Obstet Gynecol 1997;90:210-5.

28. Naeye RL. Maternal age, obstetric complications, and the outcome of pregnancy. Obstet Gynecol 1983;61:210-6.

29. Jackson RA, Gibson KA, Wu YW, Croughan MS. Perinatal outcomes in singletons following in vitro fertilization: a meta-analysis. Obstet Gynecol 2004;103:551-63.

30. Romundstad LB, Romundstad PR, Sunde A, von Düring V, Skjaerven $R$, Vatten $L$. Increased risk of placenta previa in pregnancies following IVF/ICSI; a comparison of ART and non-ART pregnancies in the same mother. Hum Reprod 2006;21:2353-8.

31. Paulson RJ, Boostanfar R, Saadat P, Mor E, Tourgeman $D E$, Slater $C C$, et al. Pregnancy in the sixth decade of life: obstetric outcomes in women of advanced reproductive age. JAMA 2002;288:2320-3.

32. Bianco A, Stone J, Lynch L, Lapinski R, Berkowitz G, Berkowitz RL. Pregnancy outcome at age 40 and older. Obstet Gynecol 1996;87:917-22.

33. Zhu C, Wang M, Niu G, Yang J, Wang Z. Obstetric outcomes of twin pregnancies at advanced maternal age: a retrospective study. Taiwan J Obstet Gynecol 2018;57:64-7.

34. Delbaere I, Verstraelen H, Goetgeluk S, Martens G, Derom $C$, De Bacquer $D$, et al. Perinatal outcome of twin pregnancies in women of advanced age. Hum Reprod 2008;23:2145-50. 


\section{Obstetrics \& Gynecology Science}

Vol. 62, No. 2, 2019

35. Blickstein I, Keith LG. Aging, twinning, and perinatal outcomes. Fertil Steril 2003;79:661.

36. Strobino DM, Ensminger ME, Kim YJ, Nanda J. Mechanisms for maternal age differences in birth weight. Am J Epidemiol 1995;142:504-14.

37. Lee KS, Ferguson RM, Corpuz M, Gartner LM. Maternal age and incidence of low birth weight at term: a population study. Am J Obstet Gynecol 1988;158:84-9.

38. Hack KE, Derks JB, Elias SG, Franx A, Roos EJ, Voerman SK, et al. Increased perinatal mortality and morbidity in monochorionic versus dichorionic twin pregnancies: clinical implications of a large Dutch cohort study. BJOG 2008;115:58-67.

39. Hook EB, Cross PK, Schreinemachers DM. Chromosomal abnormality rates at amniocentesis and in live-born infants. JAMA 1983;249:2034-8.

40. Meyers C, Adam R, Dungan J, Prenger V. Aneuploidy in twin gestations: when is maternal age advanced? Obstet Gynecol 1997;89:248-51. 